\title{
Decision Support System for the Sustainable Seismic and Energy Renovation of Buildings: Methodological Layout
}

\author{
Antonio Artino ${ }^{1, *(\mathbb{D}}$, Riccardo Caponetto ${ }^{2}$, Gianpiero Evola ${ }^{2}\left(\mathbb{D}\right.$, Giuseppe Margani ${ }^{1}(\mathbb{D}$, \\ Edoardo Michele Marino ${ }^{1}\left[{ }^{(1)}\right.$ and Emanuele Murgano ${ }^{2}$ \\ 1 Department of Civil Engineering and Architecture (DICAr), University of Catania, Via S. Sofia 64, \\ 95123 Catania, Italy; margani@unict.it (G.M.); edoardo.marino@unict.it (E.M.M.) \\ 2 Department of Electrical Electronic and Computer Engineering (DIEEI), University of Catania, \\ Viale A. Doria 6, 95125 Catania, Italy; riccardo.caponetto@unict.it (R.C.); gevola@unict.it (G.E.); \\ emanuele.murgano@unict.it (E.M.) \\ * Correspondence: antonio.artino@phd.unict.it
}

Received: 12 November 2020; Accepted: 3 December 2020; Published: 9 December 2020

\begin{abstract}
In Italy, as in many other European countries, a large part of the real estate was built before the issue of restrictive regulations regarding seismic resistance and energy efficiency. Consequently, most existing buildings show inadequate structural and energy performance. However, although a combined renovation is highly recommended, and despite relevant tax incentives which are currently available, the building retrofit market is still struggling to take off. In fact, the lack of information and/or awareness of the involved parties and the consequent difficulty for condominiums to approve the retrofit works are often insuperable obstacles. A Decision Support System (DSS) may help in evaluating and comparing different combined renovation scenarios, thus promoting the regeneration of the building stock. This study presents a new methodology for the selection of the optimal building renovation scenario through a DSS, which is conceived as a tool to allow a quick, simple and effective identification of the best retrofit strategy, based on a priority scale (e.g., costs and duration of intervention, disruption to the occupants, environmental sustainability, energy savings, thermal comfort, structural safety). For this purpose, the DSS calculates suitable performance indices and relative costs. Finally, the system proposes a ranking of the best combined retrofit scenarios. This research study is still ongoing and next steps will deal with the calibration of the proposed methodology.
\end{abstract}

Keywords: decision support system; building renovation; seismic retrofit; energy efficiency; intervention costs; cost optimal; environmental sustainability; occupants' disruption

\section{Introduction}

A large part of the real estate in Italy and in many other European countries shows inadequate structural and energy performance. One of the main causes is that these buildings were built before restrictive regulations regarding seismic resistance and energy efficiency were issued. In particular, about $75 \%$ of the Italian residential buildings were built before 1980 , when only $25 \%$ of the national territory was classified as a seismic zone. According to the 2011 census of the Italian National Institute of Statistics (ISTAT), about two-thirds of the residential building stock was built before 1974, i.e., before the issue of the framework law for seismic-resistant structures (Law 64/1974). This is one of the main reasons for the seismic vulnerability of existing buildings: most of them were indeed designed to sustain gravity loads, without considering the effects of seismic actions. 
Furthermore, existing buildings are responsible for around $40 \%$ of the final energy demand and $36 \%$ of the global $\mathrm{CO}_{2}$ emissions. In particular, $75 \%$ of the EU building stock was built before 1990 and they are characterized by an average thermal transmittance (indicated as U-value hereafter) between 2.07 and $1.44 \mathrm{~W} \mathrm{~m}^{-2} \mathrm{~K}^{-1}[1]$, as shown in detail in Figure 1.

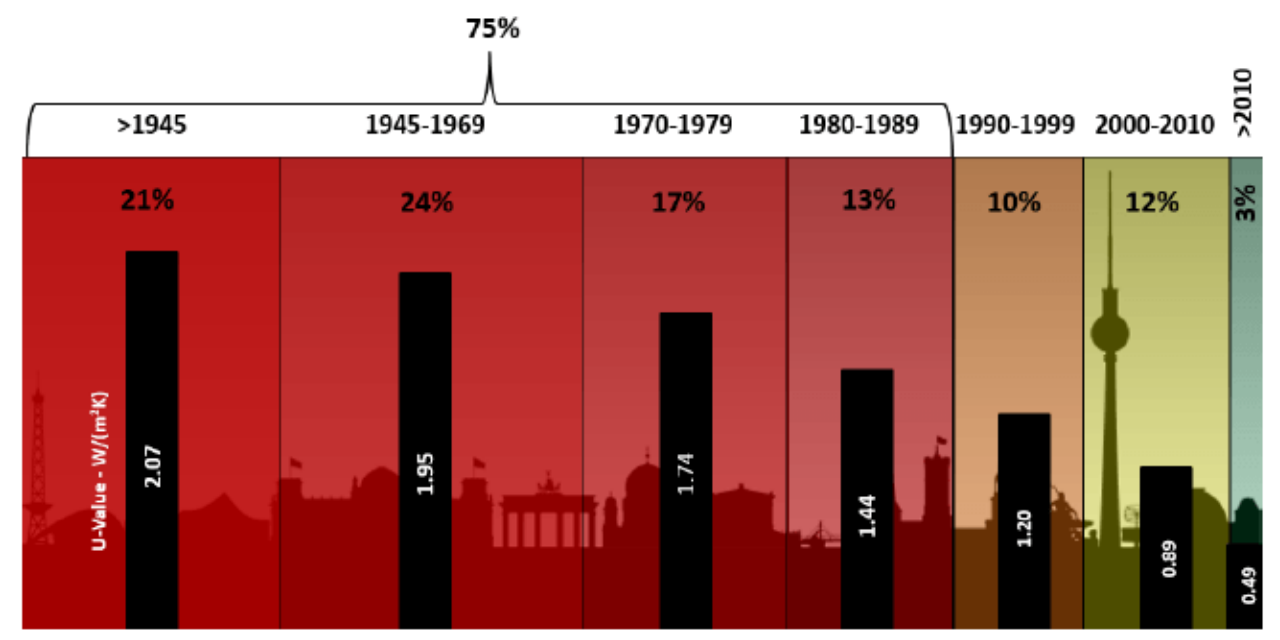

Figure 1. EU Building Stock by period of construction and U-value [2].

As regards to the Italian context, the first restrictive regulation concerning the reduction of energy consumption in buildings was Law 10/1991, issued when about $86 \%$ of the residential real estate had already been built. According to the data collected by the Buildings Performance Institute Europe (BPIE) [3], these buildings are characterized by an annual heating energy need of about 140-220 $\mathrm{kWh} \mathrm{m}^{-2}$, far beyond the limit imposed by the current national standards [4]. As a consequence, energy improvements are today mandatory in Italy in case of major renovations. In detail, when refurbishment activities involve more than $25 \%$ of the building envelope, the thermal transmittance (U-value) of the envelope components and the efficiency of the heating and cooling systems must be considerably improved.

On the one hand, during the last two decades, the European Union and the Italian government have been remarking the urgent need to reduce the energy demand of existing buildings, making relevant economic and financial efforts $[5,6]$. On the other hand, fewer steps forward have been made to reduce the seismic vulnerability of the existing building stock, mostly due to the low percentage of EU countries rated as earthquake-prone [4]. However, in some big European cities, a high percentage of the residential building stock is exposed to seismic risk (around 50\% in Italy), and urgently need interventions to improve their seismic safety and, therefore, their social sustainability. In Italy, a series of forward-looking regulations has been recently approved, aimed at encouraging interventions to reduce the seismic vulnerability of existing constructions [6].

As a matter of fact, as mentioned above, a relevant number of EU buildings are currently inadequate in terms of both seismic and thermal performance, therefore, an integrated or combined renovation strategy is highly recommended. Such an approach can offer multiple benefits at the same time, making the retrofit process far more sustainable. A first advantage is related to the possibility of dealing with two critical issues in a sustainable way through a single solution: in fact, both retrofit operations can be carried out simultaneously, thus avoiding additional costs, longer construction times and disruption to the occupants, as it happens in cases of separated and unrelated interventions. Furthermore, the quality of an integrated project is certainly higher, because all the matters and demands are simultaneously worked out.

According to these observations, the Italian 2019 Financial Law [7], confirmed the so-called "Sisma Bonus" and "Eco Bonus": the former allows incentives granted in the form of tax credits ranging between $50 \%$ and $85 \%$ of the total cost, on a total amount of retrofitting expenditure not exceeding 
$€ 96,000$ per property unit (apartment, single family house, etc.); the latter, incentives between $50 \%$ and $75 \%$ of the total cost not exceeding $€ 40,000$ per property unit. Moreover, the Italian government has proved to be a pioneer in Europe, offering the possibility of combining tax incentives for seismic and energy upgrading in case of combined interventions. In fact, incentives can be increased up to $75 \%$ in case of improvement of one seismic risk class [8] and up to $85 \%$ if an increase of two risk classes are achieved: in both cases, the maximum retrofitting expenditure amounts to $€ 136,000$ per property unit. Moreover, following the recent coronavirus pandemic, a special "Super Bonus" [6] up to 110\% was issued: it is applied to a large range of interventions related to building energy improvement, installation of more performant thermal plants and renewable energy source (RES) systems, but also to seismic upgrading. The abovementioned main tax incentives are summarized in Table 1, where the amount of annual tax credit installments is indicated.

Table 1. Comparison between the main tax incentives currently available in Italy.

\begin{tabular}{cccc}
\hline Incentive & \% Tax Credits & $\begin{array}{c}\text { Max. Expenditure } \\
\text { for Each Property }\end{array}$ & $\begin{array}{c}\text { No. of Annual Tax } \\
\text { Credit Installments }\end{array}$ \\
\hline Eco Bonus & $50-75 \%$ & $€ 40,000$ & 10 \\
Sisma Bonus & $70-85 \%$ & $€ 96,000$ & 5 \\
Eco Bonus + Sisma Bonus & $80-85 \%$ & $€ 136,000$ & 10 \\
(Multi-property buildings) & $70-80 \%$ & $€ 136,000$ & 10 \\
$\begin{array}{c}\text { Eco Bonus + Sisma Bonus } \\
\text { (Single-family buildings) }\end{array}$ & $110 \%$ & $€ 30,000-136,000$ & 5 \\
Super Bonus & &
\end{tabular}

In addition, a useful and convenient mechanism for the tax credit transfer has recently been introduced: the accrued credit can be directly moved to the involved construction companies or even to third parties (intermediaries of the transaction, e.g., banks/lenders), thus reducing or even avoiding the economic burden for the owners.

As a consequence, a significant increase in building retrofit interventions would be reasonably expected. Actually, the building retrofit market is still struggling to take off. In fact, on the one hand, the lack of information and/or awareness of the involved parties about the advantageous scenarios of deep renovation and, in case of fractional ownership, the difficulty for condominiums to approve disruptive renovation works are often insuperable obstacles. On the other hand, the high costs, the technical complexity and long duration of deep renovation, the lack of qualified companies and/or specialized professionals, make the decision-making process complex, thus discouraging property owners. Starting from these considerations, this article presents a methodology aimed at developing a Decision Support System (DSS) for the seismic and energy renovation of non-historic buildings, focused on skilled users (e.g., engineers, architects) and supporting such professionals as occupants, owners and building managers.

\section{The State of Art}

\subsection{The State of Art of Combined Retrofit Interventions}

In the recent past, several studies have suggested a combined approach to building renovation. Among all the possible combined intervention strategies, those that can be performed from the outside are more appealing [9-12], because they reduce the disruption to the occupants during the works and do not require their relocation. La Greca and Margani [4] have highlighted the advantages of combined renovation actions, indicating the barriers that currently limit such actions and suggesting possible countermeasures. A recent in-depth study [13] found that a combined retrofitting scheme will reduce substantially the payback periods in moderate to high seismicity regions: the authors applied an assessment methodology based on the evaluation of expected annual losses from energy costs and seismic losses, and therefore, the identification of an optimum retrofitting scenario was carried out. 
Some studies $[14,15]$ have proposed a three-dimensional addition (exoskeleton) to the existing building, aiming also at improving the architectural image of the property. In particular, they explored the concept of the engineered double skin facade. D'Urso and Cicero proposed mesh exoskeletons to strengthen existing buildings through a parametric approach [16], paying particular attention to the architectural image, which is too often neglected in the combined redevelopment projects. Moreover, Calvi et al. [17] propose the introduction of a "green and resilient indicator", in order to evaluate earthquake resilience and energy efficiency of existing buildings.

Bournas [18,19] proposed the use of inorganic textile-based composites combined with insulation materials to achieve the seismic and energy retrofitting of reinforced concrete (RC) structures and masonry building envelopes. Another interesting ongoing research project called Pro-GET-onE (PROactive synergy of inteGrated Efficient Technologies on buildings Envelopes) [20] suggests a holistic renewal strategy based on pre-assembled components. In this project, Ferrante et al. aim to achieve maximum performance in terms of energy efficiency, as well as social and economic security and sustainability, by adding a new highly performing envelope and new high-efficiency air conditioning and ventilation systems. The application of a new external steel frame connected to the existing building improves the structural stiffness with a minimum increase in seismic masses, with a consequent reduction in the fundamental period of vibration of the structure. However, despite being a very advantageous and effective system, the use of three-dimensional additions leads to an increase in the overall dimensions of the existing building, not always allowed by urban planning regulations.

Other authors have analyzed the effect of adding dissipative braces to the structure [21,22], which increase the building stiffness and energy dissipation capacity, with the aim of minimizing damage at the occurrence of small earthquakes. Manfredi and Masi [23], instead, proposed replacing the external infill walls with new panels with better structural and thermophysical properties; a similar strategy has been applied by Artino et al. [24], proposing to use autoclaved aerated concrete blocks infill panels. For mid-low hazard areas, this technique could imply a full rehabilitation with regards to both seismic and thermal requirements, in compliance with the regional specific rules. Another innovative energy, seismic and architectural retrofit strategy for RC framed buildings is based on the external addition of cross-laminated timber panels to the outer walls, in combination with wooden-framed panels. As recently proposed by Margani et al. [25], these prefabricated panels are connected to the existing structure through special seismic energy dissipation devices, and they also integrate insulation and cladding materials to improve both energy performance and architectural image.

\subsection{The State of Art of Decision Support Systems in the Building Renovation Sector}

As regards to the specific theme of this article, some companies and universities have already started to develop decision support tools. Kamari et al. [26] provided details on multi-criteria decision methods to be exploited in the core of a DSS. They applied a hybrid approach, based on a genetic algorithm, in order to combine and define several scenarios. The performance of the generated scenarios has been simulated and evaluated in terms of energy consumption, thermal comfort and investment costs. The ideal trade-off between the proposed criteria was identified through a Pareto front and, subsequently, the optimal scenarios were determined using evaluation methods based on Multiple Criteria Decision-Making.

In another study [27], a Domain Mapping Matrix was proposed for the sustainability criteria in renovation strategies. Following the indications of Danilovic and Browning [28], the authors proposed a specific matrix of $\mathrm{m} \times \mathrm{n}$ size for the renovation of buildings: it provides 26 retrofit categories, containing $\mathrm{m}=139$ design alternatives, and 18 sustainability criteria (internal comfort, energy efficiency, materials and waste, pollution, etc.), divided into $\mathrm{n}=118$ sub-criteria (such as, for example, indoor air quality, visual comfort, acoustic comfort, etc.).

Yang and Ogunkah [29] deeply described a multi-criteria DSS for the identification of low-cost green building materials and components, mainly addressed at providing useful information to designers for their residential housing projects. They developed a database and the entire application 
workflow using macro-in-Excel. It represents a very useful study for the conceptualization methodology of a DSS, but it is aimed at picking out the best material or component, unlike the discussed topic, which is addressed at selecting the best renovation scenario.

Moreover, Campos and Neves-Silva [30] examined the introduction of control solutions (the so-called Building Energy Management systems) when renovating an existing building, e.g., install presence sensors to optimize use of artificial lighting. Their project, called EnPROVE ("Energy consumption prediction with building usage measurements for software-based decision support"), consists in a DSS aimed at supporting investors in the selection of the most suitable renovation scenario, considering budget, financial analysis, technical and usage constraints. Although being a powerful tool for the ranking of energy-efficient long-term projects, it needs a technical consultant to define legislation and incentive schemes that can be applied in the case location. Furthermore, the renovation scenarios should be added, modified and/or removed manually by the user.

Among these studies, however, a lack of treatment of seismic vulnerability issues can be recorded. On the contrary, some interesting research studies introduce and assess combined seismic and energy renovation scenarios for the existing real estate. For instance, Leone and Zuccaro [31] have developed, within the EU-FP7 CRISMA project [32], a multi-criteria decision support system to select the optimal integrated retrofitting scenario, taking into account technical, financial and economic aspects. The proposed tool aims at enabling decision-makers and local authorities to implement policies and large-scale programs devoted to the sustainable improvement of the existing residential stock, but it does not take building energy efficiency and disruption to the occupants into account.

\section{Materials and Methods}

This section introduces a methodology for the development of a new DSS, that is to say, a user-friendly software application conceived to allow a quick, simple and effective identification of the best strategy for the combined energy and seismic retrofit of an existing building, according to a priority scale (costs and duration of intervention, occupants' disruption, environmental sustainability, availability of tax incentives, thermal comfort, structural safety, energy efficiency, etc.). The best scenarios are listed in advisability order, selecting among different, possible combined or integrated retrofit interventions (including demolition and reconstruction), thus supporting building owners, real estate managers and/or investors in identifying the most appropriate renovation scenario.

The proposed methodology will specifically focus on non-historic, non-listed buildings built after 1950 and characterized by a RC structural frame. These buildings are a significant share of the current stock in most European earthquake-prone countries, in particular in Italy; hence the outcomes can have high relevance.

\subsection{Concept Development and Programming}

The decision-making process involves several phases. In the first place, processed input data are used to create the Current State (CS) scenario of the building, i.e., a model of the baseline case. Data can be inserted by manual input and/or component type selection. General data (such as location, construction period, building typology, building construction, priority scale) allow the DSS to select a building model from a suitable database, which will drive the selection of all the other data. Moreover, requested inputs contain level and extent of possible damages incurred in the building, its state of conservation and the type and year of realization of its latest significant retrofit.

As regards to geometrical inputs, in-depth considerations are required. On the one hand, some inputs-such as the number of conditioned stories, structural stories and apartments, the total building height, the number of columns and the total window surfaces (for the main four sun expositions) — can be easily determined by inspecting the available documentation and can be thus entered with the due level of detail. On the other hand, the geometrical configuration of the building should be carefully simplified. In order to achieve a quick data entry, the proposed strategy consists in modeling an equivalent box, whose dimensions are calculated so as to keep the gross volume of the building 
unchanged. Here, the gross volume is computed as the gross average floor surface times the building average height.

Physical-mechanical data are associated with structural and energy performance information. The input parameters will be further described inside their relative sections below (Sections 3.2 and 3.3). A summary of the main input data-as an example—is reported in Table 2.

Table 2. Building modeling: a scheme of the main input data.

\begin{tabular}{ccc}
\hline General Data & Geometrical Data & Physical-Mechanical Data \\
\hline Location & Building dimensions & Story average column size \\
Construction period & Number of columns & Structural quality params \\
Building technologies & Adjacent buildings & Building envelope technologies \\
Building conditions & Total window surfaces & Energy systems \\
\hline
\end{tabular}

For the attribution of the building features, the user can choose among a selection of building components, i.e., available presets within the application libraries (alias database): for instance, one can choose a typical double-leaf infill wall, made of hollow bricks, as an external wall. Inside the aforementioned libraries, component characteristics are deduced from either the Italian UNI standards (such as UNI TS 11300-1:2014 [33], UNI 10351 [34], UNI 10355 [35], UNI EN ISO 10077-1 [36]) or literature references. However, in addition to the possibility of choosing from the libraries in relation to the construction period of the property, some data can be also inserted manually: For example, as regards to an external wall, one can specify wall width, U-value and specific weight.

At this point, as the input phase is completed, the DSS automatically generates a matrix of renovated buildings, discarding those retrofit strategies which are unsuitable for the specific case, due to boundary conditions and/or regulations. A selection of the preset renovation scenarios is shown in the following Table 3, where different energy and seismic interventions can also be combined.

Table 3. A selection of the preset renovation scenarios for intervention category.

\begin{tabular}{ccc}
\hline Seismic Renovation & Energy Renovation & New Building \\
\hline Base isolation & Roof insulation & Demolition and Reconstruction \\
RC shear walls & Windows replacement (a) & - \\
Dissipative bracings & Building envelope insulation (b) & - \\
Confinement of structural elements & Replacement of HVAC systems (c) & - \\
Exoskeleton & (b) $+(\mathrm{c})$ & - \\
\hline
\end{tabular}

The abovementioned matrix is created by changing the involved parameters-among the input data-in order to allow a renovated building assessment using the same formulas and simplified methods. For instance, a renovation scenario can provide for the confinement of structural elements and building envelope insulation. The former is realized through RC jacketing, and its relative model is created by modifying the dimensional and mechanical characteristics of rebars, in order to meet national standards. The latter is designed according to the national energy standards for the building sector [37] and it is achieved by adding an external layer of high-performing and locally-available insulation panels, so as to reach a U-value below the maximum requirement for each building component (infill walls, floors) and/or a global heat transfer coefficient $\mathrm{H}_{\mathrm{t}}^{\prime}$ under the corresponding threshold.

Afterwards, the DSS evaluates-for the suitable interventions-the structural and energy performance indices, cost and duration of construction works, environmental sustainability and occupants' disruption.

Finally, the system provides a ranking of the intervention scenarios, based on an optimizing criterion decided by the technician, in accordance with the client (users, owners and/or building manager). When more than one optimizing criterion is selected, the DSS will require the entry or selection-among the recommended ones-of a priority scale for weighting the selected evaluation 
criteria. For example, one can choose to give maximum priority to structural safety, followed by heating energy needs and Pay-Back Time (PBT), respectively. This means that the ranking will start with the strategy that provides the highest Seismic Safety index (SSi) down to the one with the lowest value of this criteria; for all cases where equal SSi values occur, the second criterion-heating energy needs, in this example-is applied; further parity situations are similarly treated, following the chosen priority scale. Subsequently, for the best selected scenarios, more detailed and in-depth analyses will be carried out, in order to guarantee greater precision of the results and less deviation from the values obtainable from a rigorous design process, which would still require considerably higher charges in terms of costs and duration. An example flowchart of the methodology workflow is shown in Figure 2.

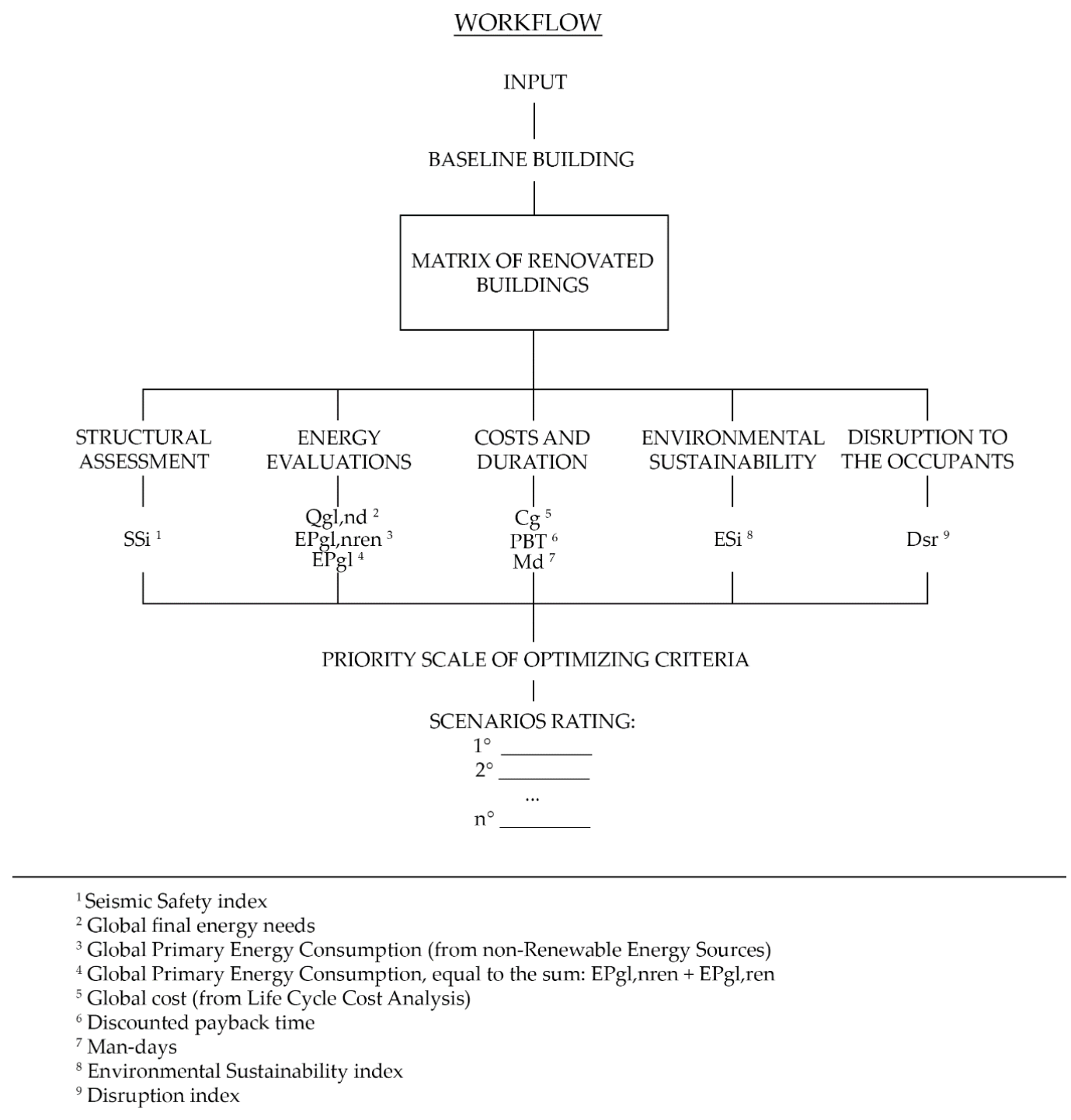

Figure 2. Workflow of the proposed methodology.

For the development of such a DSS, C\# language is proposed, using Microsoft.NET framework (Core) and following the Model-View-Controller (MVC) pattern (see [38]), typical of web-based class applications. With this framework, it is possible to develop the entire structure of the DSS, to define all the relationships between the different objects and also the front-end of such an application. The DSS is implemented and developed as a web-based application in order to avoid constraints due to different operating systems available in commerce, i.e., different Dynamic-Link Libraries (DLLs) must be written for each operating system. Furthermore, it will be accessible online, so it does not require any performing machines and hence it can be consulted from any device, like a laptop or 
smartphone, which has simple access to Internet. To the best of the authors' knowledge, this is the first web DSS-based application.

The basic element of the DSS is the 'building' object containing all the information (structural and energy) that characterize it and that will be used in subsequent decision-making phases. It has been thought as a 'model' of the aforementioned programming pattern, and it is described by a series of attributes, reported in Table 2, and methods that define the 'behavior' of the model. These attributes are unique and allow a proper characterization of the building under investigation.

All the data collected by the users are stored in a local database, in which extra attributes have to be defined according to the local applicable laws, like seismic or climatic ones. Hence, different tables are needed to perform the building characterization and renovation analysis: at present, seismic, climatic and altitude tables have been defined according to the Italian laws in order to implement as far as possible an efficient and real renovation procedure. Relationships between these different entities have been realized in order to complete the 'building' model, providing all the necessary data to define the building under investigation. Further models and methods are also implemented to realize all the renovation analysis. In particular, this former model is implemented by a series of methods which, based on the acquired information of the building, can evaluate different redevelopment scenarios, by using algorithms and methodologies (see Section 3.2, Section 3.3, and Section 3.4) for the assessment of structural and energy performance, sustainability scenarios and their implementation times and occupants' disruption. Indeed, each of the scenarios can be activated (and then calculated) when the conditions of coherence and feasibility are checked. For example, if the considered building is not suitably detached from an adjacent building, the scenarios that suggest the use of seismic isolators at the base are automatically excluded from subsequent calculations. Furthermore, another important key point of the proposed DSS is based on the interaction with third-party systems by means of Application Programming Interfaces (APIs) in order to integrate and enhance the DSS capabilities.

All the acquisition procedures, the renovation analysis, and the database relationships are performed and implemented according to the object-oriented paradigm, allowing to have coherence and a better management of the described project.

As said before, the DSS is a web-application, so it is also necessary to build a view interface and deal with the user requests: these purposes are fulfilled with the view controller of the MVC part of the applied programming pattern. The so-called "Controller", also implemented in C\#, allows to manage the HTTP requests from the user and gives contents to show them on the browser, while, the so called "View", implemented in HTML, shows the information provided by the Controller. The "View" interface can be also implemented with Cascading Style Sheet (CSS) and Bootstrap templates in order to define a custom and responsive theme/style for the DSS.

\subsection{Evaluation of Structural Performance}

Structural performance is assessed using a rapid methodology to evaluate seismic vulnerability. Some insights on the topic of seismic vulnerability reduction, therefore aimed at the conception and development of decision support methods and tools, have been recently achieved. An example is the "RE.SIS.TO Project" [39], i.e., a software based on the research studies carried out by Chinni et al. [40] at the University of Bologna and devoted to estimate the seismic vulnerability of buildings. This tool represents a user-friendly, simple and fast software, which gives the possibility to carry out vulnerability assessment, in about three days, for a residential building of standard dimensions. On the other hand, its applicability results are limited to masonry buildings and RC structures with up to seven floors. This assessment methodology finds important references in Dolce et al. [41]—who proposed a simplified linear elastic seismic analysis-and in seismic vulnerability second-level survey forms, realized by National Group for the Defense from Earthquakes (GNDT 1994) [42]. Based on a combination between qualitative and quantitative analyses, it can be used for both the analysis of the CS and possible renovation scenarios of a structure. It mainly consists of three phases: the study of the building's CS, the evaluation of its seismic capacity, intended as an estimate of the seismic acceleration that leads to 
the collapse of the building, and the comparison between the seismic capacity and seismic demand. Another interesting reference for a simplified methodology aimed at assessing seismic vulnerability of RC buildings was recently proposed by Ferreira et al. [43]. It is a qualitative method, based on the evaluation of eight parameters associated with different factors affecting the seismic response of a building (e.g., structural features, foundation conditions and position in the urban context). Relying on post-earthquake damage observation and expert opinion, they performed the parameters' formulation and their relative weight calibration.

Starting from these premises, the proposed methodology is based on a combination of qualitative and quantitative analyses. For the latter, inter alia, simplified linear elastic seismic analyses will be performed. In particular, the seismic vulnerability assessment is achieved through the comparison between the Peak Ground Acceleration (PGA) that leads the structure to the attainment of the Life Safety Limit State (SLV), PGAc (Peak Ground Acceleration capacity) and the PGA established by national standards for a Return Period of 475 years and the building location (PGAd, Peak Ground Acceleration demand).

As regards to the general and geometrical features of the RC framed structure, the main entry params are: average story weight, soil type, site topography, number of stiff frames for both $\mathrm{x}$ and $y$ directions of the building, and number of flexible frames (i.e., those with flat beams or no beams) for both $\mathrm{x}$ and $\mathrm{y}$ directions. Moreover, the proposed method requires establishing a story standard column, both in terms of geometrical and mechanical properties. This represents a very crucial phase of the assessment procedure. The standard column is intended as a column created in such a way that, if all the columns of the same story were the same as the standard column, the story lateral resistance would be the same to that of the corresponding story of the real building. Therefore, for each story, it is necessary to determine a standard column, its cross-section dimensions and rebars. Since this process could result in being tricky, an input control system is arranged. In particular, it consists in a structural library containing four pre-designed structures. These baseline models are carried out simulating the design of a typical structure-with standard dimensions and materials-according to either past praxis (before Law 64/74) or national standards (after Law 64/74, up to current national standards NTC18 [44]). Every piece of additional information inserted by the user modifies the baseline structure at its design phase, thus allowing to refine the model.

Going into detail, the procedure allows the calculation of the shear resistance of a standard column for each floor and the determination of the relative resisting moment, obtained by using an MN domain at the Ultimate Limit State (SLU) for an assigned value of normal stress. Therefore, the shear resistance is evaluated for every column of each floor and in both $\mathrm{x}$ and $\mathrm{y}$ directions of the building, applying the simplifying hypothesis of the direct proportionality between the shear resistance and the moment of inertia of the cross-section. Adding all the values obtained separately for the two directions, two shear resistances are identified for each story; the lower value between the two directions represents the story shear resistances that will be compared with the one obtained by applying a distribution of equivalent horizontal forces determined by unit spectral acceleration (reference story shear demand). The ratio between the story shear resistance and the reference story shear demand provides an indicator of the structural performance of a building's stories. It also allows the identification of the most vulnerable story and thus establishes seismic capacity in terms of spectral acceleration $\left(\mathrm{S}_{\mathrm{a}, \mathrm{c}}\right)$. Actually, this acceleration value is obtained through a simplified method, without considering the real complexity of the case. For this reason, a qualitative adjustment is recommendable. This purpose is achieved by exploiting 7 of the 11 parameters contained within the second-level seismic vulnerability survey forms (GNDT 1994), as recently modified and proposed by Ferreira et al. [43], discarding the only parameter related to the building site, because this aspect is already taken into account within the definition of SLV design spectra. The seven parameters-context-related position, seismic design type, plan irregularity, elevation irregularity, soft-story mechanism, presence of short columns, presence of other vulnerable elements - can be entered by DSS users through the selection of predefined alternatives. The parameters are used to obtain a corrective coefficient of the shear 
strength of the building, determined with the mechanical criterion above described. Four vulnerability classes (A, B, C and D) are associated to each of the seven parameters (P1-P7); therefore, every class is related to a proper score $\mathrm{C}_{\mathrm{vi}}$ and its weight $\mathrm{w}_{\mathrm{i}}$ compared to the others. Following, for each parameter, the product $\mathrm{K}_{\mathrm{i}}=\mathrm{C}_{\mathrm{vi}} \cdot \mathrm{w}_{\mathrm{i}}$ is evaluated. Information about these qualitative parameters and their relative classes and weights are shown in the summarizing Table 4. For further information, one can refer to Ferreira et al. [43].

Table 4. Qualitative parameters and relative classes and weights.

\begin{tabular}{lcccccc}
\hline \multirow{2}{*}{ Parameter } & \multicolumn{4}{c}{ Class Cvi } & \multirow{2}{*}{ Weight wi } \\
\cline { 2 - 5 } & A & B & C & D & \\
\hline P1_Context-related position & 0 & 5 & 20 & 50 & 0.5 \\
P2_Seismic design type & 0 & 5 & 20 & 50 & 1.5 \\
P3_Plan irregularity & 0 & 5 & 20 & 50 & 2 \\
P4_Elevation irregularity & 0 & 5 & 20 & 50 & 2 \\
P5_Soft-story mechanism & 0 & - & - & 50 & 2 \\
P6_Presence of short columns & 0 & 5 & 20 & 50 & 2 \\
P7_Presence of other vulnerable elements & 0 & 5 & 20 & 50 & 0.5 \\
\hline
\end{tabular}

The reduction factor $C_{\text {rid }}$ is determined by the relationship in Equation (1):

$$
\mathrm{C}_{\text {rid }}=\sum_{\mathrm{i}}{ }^{7}\left(1-\alpha \cdot \mathrm{K}_{\mathrm{i}} \cdot \mathrm{K}_{\mathrm{pegg}}{ }^{-1}\right)
$$

where $K_{\text {pegg }}$ is the sum of the $K_{i}$ in the worst class and $\alpha$ is a coefficient defined a priori by method calibration (cfr. [40]).

Finally, it is necessary to convert the spectral acceleration value $\left(S_{a, c}\right)$ into the PGAc, in order to define the earthquake entity that the structure can withstand without collapsing. Since the calculated $S_{a, c}$ is a linear-static value, the relationship between $S_{a, c}$ and PGAc is linear, as described by Dolce et al. [41].

In the end, the SSi (Seismic Safety index) is calculated as the ratio between PGAc and PGAd. SSi represents the main indicator of the structural performance and it will be used by the DSS in its decision-making operations. The lower the SSi ratio, the lower the safety degree achievable by means of a specific combined renovation strategy.

As regards to the SSi evaluation for the retrofitted scenarios, further considerations need to be made. First of all, base isolation of the structure is associated to the seismic demand reduction, which implies the increase of the PGAc and afterwards of the SSi. The PGAc potential increase is estimated according to literature formulas and comparison with observed real cases. Seismic retrofit through RC septa insertion is conceptually based on the structural strengthening and ductility increase. In this case, the retrofitted scenario is modeled starting from the CS building and modifying some quantitative and qualitative parameters. In particular, dimension and reinforcement for the standard column and qualitative classes for P2-P7, because structural stiffness irregularities can be reduced and soft-story mechanisms are more likely to be avoided. Moreover, dissipative braces can considerably increase the seismic dissipation capacity. For this aspect, further investigations are still ongoing within the authors' research group. Lastly, the intervention based on the confinement of structural elements is modeled starting from the CS building and by modifying the following parameters: dimension and reinforcement for the standard column and qualitative classes for P2-P7.

In conclusion, every described scenario is conceived in such a way that, as a function of the given building, a basic design can be immediately associated in accordance with the national standards.

\subsection{Evaluation of Energy Performance}

As far as the energy demand is concerned, the so-called "simplified method" is one of the calculation methods allowed by the Ministerial Decree 26 June 2015 [45] to perform Energy Performance Certification (APE). 
Among the open-source tools that rely on a simplified method, the most common one is DOCET [46], developed by ITC-CNR and ENEA. This tool and the corresponding simplified methodology are applicable to existing residential buildings only, provided that they have a net useful area below $200 \mathrm{~m}^{2}$. Therefore, it is suitable for the majority of sales or property leasing cases, except for cases where an APE is drawn up as a result of a major renovation. Its certification is processed in compliance with the Minimum Requirements Ministerial Decree [37] and updated to recent national standards. In particular, UNI TS 11300-part 1 (2014) [33] concerns the evaluation of energy need for space heating and cooling, while UNI TS 11300-part 2 (2014) [47] deals with the computation of primary energy need and with energy systems' efficiencies for space heating and domestic hot water production, but also ventilation and lighting for non-residential buildings. UNI 10349 (2016) [48] is the Italian up-to-date climatic database, and can be used for climatic analyses, e.g., for the computation of solar heat gains.

The methodology proposed in this paper relies on the procedures for calculating energy needs, widely described in the UNI standards mentioned above, similarly to the structure of DOCET itself. The main simplification consists in the data entry by the users, with the aim of allowing simple, quick and effective input. In fact, users are not supposed to be expert technicians in every involved building sector. The main data requested as input are those relating to the land and urban context (province, municipality and presence of adjacent buildings), building data (year of construction, external finish color and geometric data), presence of unheated rooms (basement or garage, attic, stairwell and other rooms), and thermophysical characteristics of the opaque and transparent envelope.

As regards to the geometrical data, the trickiest aspect is the need of simplifying the plan configuration. In particular, users are supposed to enter only building length and width, without taking into account any plan irregularities. This requires a preliminary definition of a rectangle plan with an equivalent gross floor surface and a common extension (i.e., same total length). An example of the equivalent plan definition is shown in Section 4.1.

Similarly, building height is calculated in relation to an equivalent-box global volume, built upon the above-described equivalent rectangle.

Afterwards, the energy analysis is based on the selection of building envelope technologies (both opaque and transparent components). The detailed imputation of each single material and/or component is not required; in fact, the user can choose among a selection of building components (see Section 3.1 for further information).

The energy performance of residential buildings is estimated in relation to the annual final energy needed to meet the thermo-hygrometric comfort requirement in relation to a standard use of a building. It corresponds to the annual energy demand for heating $\left(\mathrm{Q}_{\mathrm{H}, \mathrm{nd}}\right)$, cooling $\left(\mathrm{Q}_{\mathrm{C}, \mathrm{nd}}\right)$ and production of hot water for sanitary use $\left(\mathrm{Q}_{\mathrm{HW}, \mathrm{nd}}\right)$. The former can be calculated using the following Equations (2) and (3), through monthly-based energy balances:

$$
\begin{aligned}
& Q_{\mathrm{H}, \mathrm{nd}}=\left(\mathrm{Q}_{\mathrm{H}, \mathrm{rr}}+\mathrm{Q}_{\mathrm{H}, \mathrm{ve}}\right)-\eta_{\mathrm{H}, \mathrm{gn}} \cdot\left(\mathrm{Q}_{\mathrm{SOL}}+\mathrm{Q}_{\mathrm{END}}\right) \\
& \mathrm{Q}_{\mathrm{C}, \mathrm{nd}}=\left(\mathrm{Q}_{\mathrm{SOL}}+\mathrm{Q}_{\mathrm{END}}\right)-\eta_{\mathrm{C}, \mathrm{gn}} \cdot\left(\mathrm{Q}_{\mathrm{C}, \mathrm{tr}}+\mathrm{Q}_{\mathrm{C}, \mathrm{ve}}\right)
\end{aligned}
$$

where $\mathrm{Q}_{\mathrm{H}, \mathrm{rr}}$ is the heat loss for transmission, $\mathrm{Q}_{\mathrm{H}, \mathrm{ve}}$ is the heat loss for ventilation, $\mathrm{Q}_{\mathrm{SOL}}$ and $\mathrm{Q}_{\mathrm{END}}$ represent heat gains, respectively, from solar and internal sources, $\eta_{\mathrm{H}, \mathrm{gn}}$ is the utilization factor of the heat gains and $\eta_{C, g n}$ is the utilization factor of the heat losses.

Furthermore, in order to calculate the annual energy demand for hot water preparation $\left(\mathrm{Q}_{\mathrm{HW}, \mathrm{nd}}\right)$ Equation (4) is used:

$$
\mathrm{Q}_{\mathrm{HW}, \mathrm{nd}}=\mathrm{d} \cdot \rho_{\mathrm{w}} \cdot \mathrm{c}_{\mathrm{w}} \cdot \mathrm{V}_{\mathrm{w}} \cdot \Delta \theta_{\text {supply-net }}
$$

Here, $V_{\mathrm{w}}$ is the daily water volume needed that, in residential buildings, can be estimated in about $50 \mathrm{~L}$ per capita. Moreover, in Equation (4) d is the number of days, $\rho_{\mathrm{W}}$ and $\mathrm{c}_{\mathrm{W}}$ stand, respectively, for water density (i.e., $1000 \mathrm{~kg} \mathrm{~m}^{-3}$ ) and its specific heat (i.e., $1.162 \times 10^{-3} \mathrm{kWh} \mathrm{kg}^{-1} \mathrm{~K}^{-1}$ ), and $\Delta \theta_{\text {supply-net }}$ is the difference between supply and net water temperatures. 
In the end, the global annual energy demand $\left(\mathrm{Q}_{\mathrm{gl}, \mathrm{nd}}\right)$ is computed as the monthly-based sum of the three demand values for each energy service.

As far as the technical systems are concerned, the main entry data are related to the features of the heat generator (biomass generator, heat pump, boiler) and the types of emission terminals and regulation and distribution systems. Moreover, a corresponding efficiency is attributed to each of those aspects (respectively called $\eta_{\mathrm{gn}}, \eta_{\mathrm{em}}, \eta_{\mathrm{reg}}, \eta_{\mathrm{d}}$ ); in the end, for every energy service, global energy efficiency $\eta_{\mathrm{gl}}$ is determined by means of the Equation (5):

$$
\eta_{\mathrm{gl}}=\eta_{\mathrm{gn}} \cdot \eta_{\mathrm{em}} \cdot \eta_{\mathrm{reg}} \cdot \eta_{\mathrm{d}}
$$

The values of the aforementioned efficiencies are collected from the tables available within the national standards [47] — and they are retrieved according to the features of the systems available in the building. In this sense, two cases can occur: if the energy system is centralized then the relative data is entered only once; otherwise, if the systems are autonomous, then the user is supposed to choose- through a guided procedure-three apartments whose systems are statistically representative of the entire building plants. In the latter case, $\eta_{\mathrm{gl}}$ is computed as the weighted average compared to the number of apartments.

In addition, the description of any renewable energy sources (photovoltaic and/or thermal) should be faced. Three main parameters are required: system typology, total surface of panels and predominant sun exposure.

Furthermore, some useful energy criteria are computed. They consist in the global primary energy consumption from non-renewable sources $\mathrm{EP}_{\mathrm{gl}, \mathrm{nren}}$ and global primary energy consumption from renewable sources $\mathrm{EP}_{\mathrm{gl}, \mathrm{ren}}$. In particular, the global consumption of primary energy is evaluated by dividing the annual energy needs $\left(Q_{H, n d}, Q_{C, n d}\right.$ and $\left.Q_{H W, n d}\right)$ by the global energy efficiency $\eta_{\mathrm{gl}}$ of each respective energy system, and then by applying suitable conversion factors related to the energy source (fuel, electricity). Therefore, by subtracting the production of energy from renewable sources $\left(\mathrm{EP}_{\mathrm{gl}, \mathrm{ren}}\right)$, evaluated on a monthly basis with simplified formulas, it will be possible to obtain the non-renewable primary energy consumption $\left(\mathrm{EP}_{\mathrm{gl}, \mathrm{n} r e n}\right)$.

Finally, the sum of the aforementioned annual values of final energy needs $\left(Q_{\mathrm{gl}, \mathrm{nd}}\right)$ and the global consumption of primary energy $\left(\mathrm{EP}_{\mathrm{gl}, \mathrm{nren}}+\mathrm{EP}_{\mathrm{gl}, \mathrm{ren}}\right)$ set the two characteristic criteria for the energy performance comparisons and, therefore, the DSS exploits them within the decision-making process.

\subsection{Evaluation of Costs, Work Duration, Environmental Sustainability and Occupants' Disturbance}

The considered retrofit strategies are assessed and compared under an economic point of view by applying the cost optimal analysis method and by estimating the discounted payback time (PBT). The former method is based on the calculation of the global cost associated to a building life cycle [49,50] — the so-called Life Cycle Cost (LCC)—aimed at finding the cost optimal energy level and seismic rating, which is defined as energy [51] and seismic performance levels leading to the lowest cost over the estimated/expected life cycle period.

The global cost $\left(\mathrm{C}_{\mathrm{g}}\right)$ of each retrofit scenario is computed by adding the initial investment or construction costs $\left(C_{C}\right)$, the sum of the annual operational costs for every year $\left(C_{a, i}\right)$ discounted by the real rate of interest $r_{d i s, i}$, and the final value $V_{a l F}$, all with reference to the starting year of the calculation period [52]. The annual operational costs $C_{a}$ include recurrent costs (such as maintenance and energy carriers). The real rate of interest $r_{\text {dis }}$ is calculated through financial mathematic formula, taking into account the nominal rate of interest $i$ and the rate of inflation $p$, continuously kept up-to-date with the financial markets, i.e., according to European Central Bank data. An important benchmark for the $\mathrm{C}_{\mathrm{g}}$ definition and evaluation was found in 244/2012/EU [53] and EN 15459 Regulations [54], where a calculation period of 30 years is suggested for residential and public buildings. 
In order to properly establish the priorities among energy and seismic retrofit strategies, the discounted PBT was therefore estimated, by means of the following equation:

$$
\mathrm{PBT}=\mathrm{C}_{\mathrm{C}} \cdot \mathrm{NPV}^{-1} \text {. }
$$

PBT calculations require an evaluation of the net present value (NPV), defined as the sum of the present incoming and outgoing cash flows and the current value for a certain period. Moreover, both $\mathrm{C}_{\mathrm{g}}$ and PBT criteria take into account the available tax incentives as a discount applied to the current construction costs. Finally, possible retrofit scenarios are compared by means of $C_{g}$ and PBT.

In detail, the amount of $C_{C}$ associated with each combined intervention strategy is estimated by means of standard metric computations, based on the evaluation of costs associated to every predicted kind of construction work. Generally, geometric data is easily deductible from a building survey and/or technical drawings, while the average cost of all the needed operations is not immediate and generalizable, since it results from several specific parameters (i.e., building technologies and materials) and, particularly in Italy, it varies from region to region. Therefore, preliminary investigations of the building work regional price lists were necessary: Sicilia (Southern Italy), Lazio (Central Italy) and Lombardia (Northern Italy) building price lists were considered in this study.

Furthermore, annual operational costs $\left(\mathrm{C}_{\mathrm{a}, \mathrm{i}}\right)$ are evaluated in relation to the building management plan and operative costs. With regards to the former aspect, a floor area assessment method is here proposed, while only the preventive building maintenance is predicted for all the renovation cases. From the structural point of view, earthquake-related economic losses are estimated in terms of Expected Annual Losses (EAL), by means of a probabilistic approach. In this direction, different methodologies have already been developed. One of these is the Italian Sisma Bonus simplified procedure, which was chosen within this study because of its simple and immediate application to the Italian real estate scenario, therefore allowing a quick computation of the available financial incentives. This methodology is based on the evaluation of two indices: Risk Index (IS-V) - here assumed equal to SSi as defined in Section 3.2-and EAL, estimated by means of conventional repair costs (as percentage of reconstruction costs) associated to each performance level (or limit state) established by the Italian standards $[44,55]$. In the end, for the economic analysis, EAL are associated to every possible retrofit scenario within their annual operational costs $\left(C_{a, I}\right)$.

As regards to the duration of retrofit operations, an approximate calculation in terms of Man-days $(\mathrm{Md})$ is here proposed. This parameter represents an estimation of the total working days necessary for the realization of a given renovation scenario. $\mathrm{Md}$ are calculated according to the $\mathrm{Cc}$, the incidence of labor (Li) and the average hourly cost of a worker (ahC), according to the following Equation (7):

$$
\mathrm{Md}=\mathrm{CC} \cdot \mathrm{Li} \cdot \mathrm{ahC}^{-1} \text {. }
$$

Once the Md parameter is known, it is possible to obtain an evaluation of the duration of the intervention by dividing it by the average number of workers expected on site daily.

As regards to the environmental sustainability assessment, one of the most widely used methods on the international panorama is based on Life Cycle Assessment (LCA) of products and/or production processes [56].

Upstream of these assessments is the collection and analysis of data on environmental impacts (e.g., emissions, waste production and consumption of resources) which are associated with a product starting from the extraction of the necessary raw materials, and the process production and use, up to final disposal, including recycling, reuse and/or energy recovery.

In the case of the building sector, the ITACA protocol [57] constitutes a well-tested reference in the Italian territory for the application of the LCA to a building. The structure of the protocol varies according to the intended use, the type of intervention and the context. It is based on a system of assigning partial scores, between -1 and 5 , according to the degree of satisfaction of certain requirements (called Criteria). In fact, this protocol is structured according to a hierarchical scale which 
finds in the Criteria the basic elements; each criterion is a discriminating item for the achievement of a certain partial score. Criteria are grouped into Categories, which are included within the Evaluation Areas: Site Quality, Consumption of Resources, Environmental Loads, Environmental Quality, Service Quality. These areas are divided into the two macro-categories (Tools) of the Site and the Building. The aforementioned score is then affected by a relative weight, obtained by means of a performance scale (benchmark); the weight represents, in fact, the degree of importance of the Criterion in the ITACA Protocol of reference, and is determined by estimating its environmental impact. The sum of all partial weighted scores represents the overall score, according to the rating scale set by the protocol.

As part of this research, given the high amount of data to be managed, it is considered appropriate to restrict the number of criteria considered to those pertaining to the following assessment areas and categories:

- B.1 Primary energy required during the life cycle (B.1.2 Non-renewable primary energy; B.1.3 Total primary energy);

- $\quad$ B.3 Energy from renewable sources (B.3.2 Renewable energy for thermal uses; B.3.3 Energy produced on the site for electrical uses);

- B.4 Eco-compatible materials (B.4.1 Reuse of existing structures; B.4.6 Recycled/recovered materials; B.4.7 Materials from renewable sources; B.4.8 Local materials; B.4.10 Recyclable or demountable materials; B.4.11 Certified materials);

- $\quad$ B.6 Performance of the envelope (B.6.1 Net heating thermal energy; B.6.2 Net cooling thermal energy; B.6.3 Average global heat exchange coefficient; B.6.4 Control of solar radiation);

- C.1 $\mathrm{CO}_{2}$ equivalent emissions (C.1.2 Emissions expected in the operational phase);

- C.3 Solid waste (C.3.2 Solid waste produced in the retrofitting phase);

- $\quad$ D.3 Thermo-hygrometric well-being (D.3.2 Operating temperature in summer).

Some of the aforementioned criteria (e.g., B.4 and C.3) are pre-established on the basis of appropriate estimates, taking into account the type of work envisaged and the on-site availability of the building materials necessary for the completion of a specific renovation strategy. These evaluations can be achieved through a City-Strategy-Criterion preliminary association. On the other hand, several criteria (such as B.1 and B.3), can be obtained from the results of the energy calculations described above.

Following the described procedure, the total score (ESi, Environmental Sustainability index) is determined for each combined renovation strategy admissible for the given building.

Finally, the introduction of the Disturbance parameter (Dsr) is here proposed in order to estimate the disturbance caused to the occupants by the retrofit operations. This factor is estimated as a function of the invasiveness (invasive, partially invasive, low-invasive) of the planned intervention, the duration of the disruptive works, as well as the costs and times related to the eventual displacement of the occupants or to the partial dysfunctionality of the real estate. In particular, for a strategy that includes only low-invasive interventions, Dsr assumes a value of zero. This occurs, for example, when the operations are conducted mainly from the outside or, provided that for short times and for limited spaces of the housing units, also inside the building. However, when operations are so invasive to require a displacement of the occupants, the Dsr assumes a value greater than 0 and is quantified by operating the sum between the days of re-housing and the product of the days of partial inactivity for a weighing coefficient $\mathrm{Kd}$; the latter may vary according to the size and importance of the unusable space and takes values between 0 (no disturbance) and 1 (maximum disturbance: e.g., unusable bedrooms).

\section{Results and Discussion}

The presented research study is still ongoing, but significant steps have already been made. As regards to the software conceptualization and programming, it has been designed and set up as described in Section 3.1, but assessment methodologies are not fully implemented yet and they will be the object of further developments. In particular, concerning the structural performance, its evaluation has been partially implemented for the baseline building, but it is not currently available for the matrix 
of renovated buildings. As regards to the energy performance, however, the computation codes are completed for the baseline building and partially completed for the intervention scenarios. Furthermore, the basic formulations about costs and duration of retrofitting works have been implemented. Finally, as regards to the assessment of the environmental sustainability of retrofit scenarios, the methodology has been identified and adapted to the purposes of this research.

The next step of this research will deal with the completion of the programming setup related to the aforementioned assessment methodologies. Moreover, further steps will deal with the calibration of the methodology through its application to an appropriate number of buildings, the comparison of the results to the ones of other consolidated tools, as well as the possibility to apply artificial intelligence techniques and fuzzy logic approach to the DSS.

In order to achieve a preliminary validation of the energy assessment methodology, the following case study was simulated with two different tools, namely the energy evaluation approach proposed in this paper and the quasi-static monthly calculation method used for the building energy certification in Italy and included in several commercial software tools. In this study, Blumatica Energy (BME) has been used.

\subsection{Case Study}

The energy analyses were performed for an apartment block located in via Santo Cantone in Nesima, a western suburb of the metropolitan city of Catania (Sicily). The selected building is representative of a large part of the Italian residential stock built between the 1950s and 1980s. It consists of four stories, with two apartments per story, a pitched roof and no underground floor. The shape is roughly rectangular and measures $18.1 \mathrm{~m}$ by $11.8 \mathrm{~m}$. The global gross and useful floor area are around 816 and $725 \mathrm{~m}^{2}$, respectively. In order to define an equivalent rectangle plan (as mentioned in Section 3.3), a simplified plan model was considered, as reported in the following Figure 3.

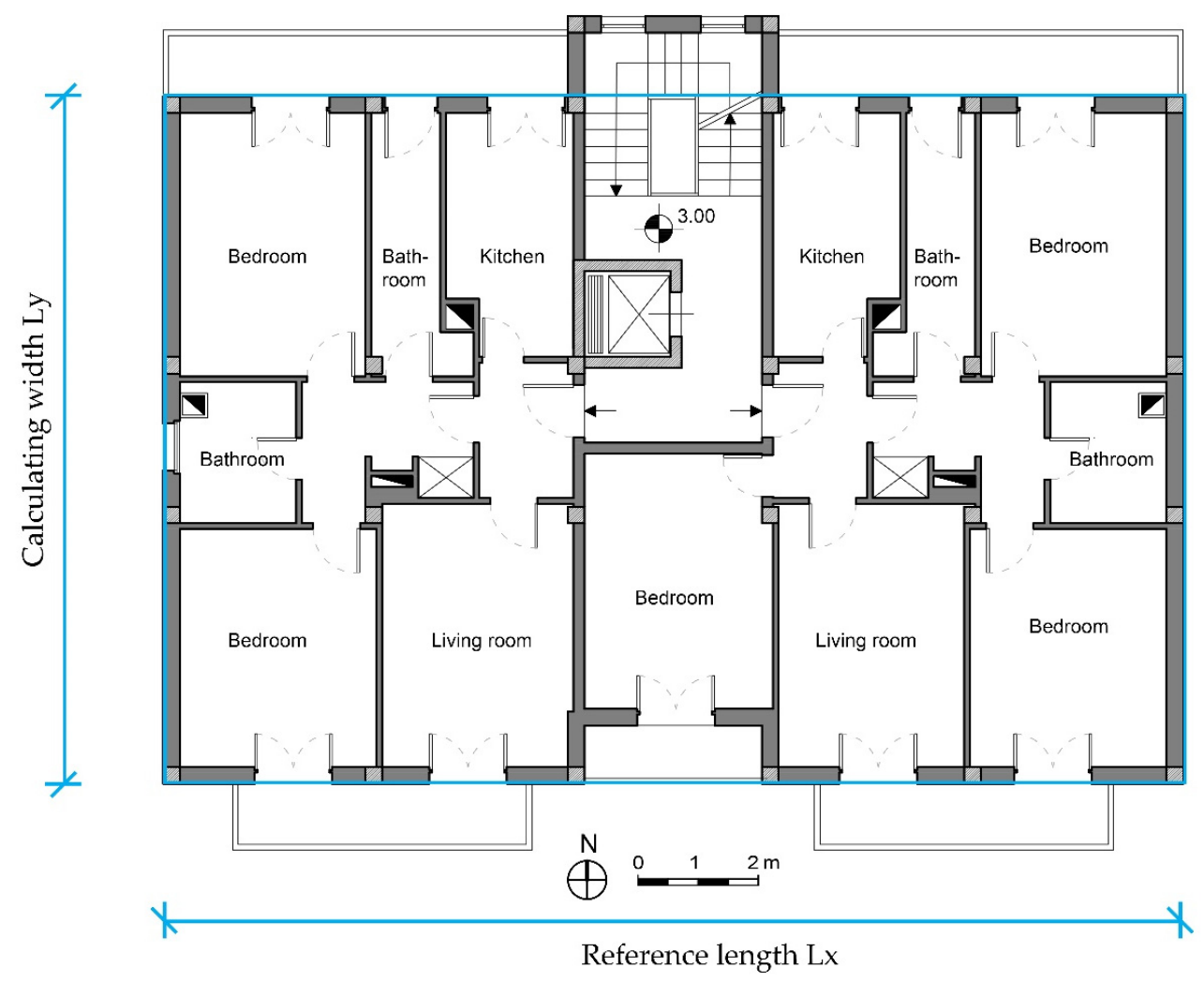

Plan Model

Figure 3. Building type plan and simplified plan model. 
In the first place, the greater building extension was chosen as a reference; in this case, the building length (Lx). Afterwards, the calculating rectangle width Ly is determined as the ratio between the gross floor area and Lx. Finally, the gross measures were transformed into net measures by reducing each dimension by $9 \%$, i.e., by multiplying gross surfaces and volumes by 0.81 and 0.73 , respectively.

\subsection{Evaluation of Energy Needs}

As regards to building technologies and materials, according to the construction techniques adopted in the considered period, double-leaf masonry infill walls are present, with $8 \mathrm{~cm}$ (internal leaf) and $12 \mathrm{~cm}$ (external leaf) thick blocks of hollow clay bricks, plus an intermediate $10 \mathrm{~cm}$-thick empty cavity (without insulation). The windows have aluminum frames without thermal break and single clear glass. An external plastic rolling shutter is located in front of each window. Both the bottom and the attic floor are formed by a $20 \mathrm{~cm}$-thick hollow-core concrete slab with no insulation. U-values are corrected according to UNI standards, in order to account for deviations from default conditions in the building component. For instance, the base floor heat dissipation is different than the attic floor, because their boundary conditions are different (ground and unheated attic, respectively). The main physical information of building components, and their relative corrected U-values, are summarized in Table 5.

Table 5. Qualitative parameters and relative classes and weights.

\begin{tabular}{ccc}
\hline Building Component & Materials/Technology & U-Value, Corr. (W $\mathbf{~ m}^{-\mathbf{2}} \mathbf{K}^{\mathbf{1}}$ ) \\
\hline External infill wall & Double-leaf of hollow bricks & 1.085 \\
Base floor & Hollow-core concrete slab & 0.440 \\
Internal floor & Hollow-core concrete slab & 1.830 \\
Attic floor & Hollow-core concrete slab & 1.867 \\
Windows & Aluminum, float glass & 4.237 \\
Rolling shutter box & Aluminum, non-insulated & 6.000 \\
\hline
\end{tabular}

Furthermore, other simulation assumptions were made, such as a constant ventilation rate of 0.3 air changes per hour $(\mathrm{ACH})$. The main internal heat gains are due to people and they are estimated in $2.5 \mathrm{~W} \mathrm{~m}^{-2}$. Moreover, the thermostat was set to $26{ }^{\circ} \mathrm{C}$ in summertime and $20{ }^{\circ} \mathrm{C}$ during the heating season. The heating season was considered between 1 December and 31 March (121 days), according to national standards guidelines, while the cooling period was assumed between 1 June and 30 September (122 days).

The results were compared in terms of annual energy needs $\left(\mathrm{Q}_{\mathrm{H}, \mathrm{nd}}, \mathrm{Q}_{\mathrm{C}, \mathrm{nd}}\right.$ and $\left.\mathrm{Q}_{\mathrm{HW}, \mathrm{nd}}\right)$. They show an acceptable deviation between the two methods, although they are affected by some further described simplifications. Table 6 displays a summary of energy results and their relative deviation, intended as the ratio between the values difference and the value from the commercial software. For instance, the relative deviation associated to $\mathrm{Q}_{\mathrm{H}, \mathrm{nd}}$ is evaluated as follows in Equation (8):

$$
\mathrm{Q}_{\mathrm{H}, \mathrm{nd}}=(31,420-30,403) \cdot 30,403^{-1}=3.3 \% \text {. }
$$

Table 6. Results comparison and relative deviation for each energy service.

\begin{tabular}{cccc}
\hline Annual Energy Needs & Proposed Methodology & Commercial Software & Relative Deviation \\
\hline Heating $\left(\mathrm{Q}_{\mathrm{H}, \mathrm{nd}}\right)$ & $31,420 \mathrm{kWh}$ & $30,403 \mathrm{kWh}$ & $3.3 \%$ \\
Cooling $\left(\mathrm{Q}_{\mathrm{C}, \mathrm{nd}}\right)$ & $20,377 \mathrm{kWh}$ & $20,806 \mathrm{kWh}$ & $-2.1 \%$ \\
Hot water $\left(\mathrm{Q}_{\mathrm{HW}, \mathrm{nd}}\right)$ & $8604 \mathrm{kWh}$ & $8632 \mathrm{kWh}$ & $-0.3 \%$ \\
\hline
\end{tabular}

The deviations are relatively low and acceptable for the purposes of this methodological approach, especially if one takes into account the various simplifications introduced. 
The main differences between the two calculation methods are related to the following factors:

- Sky and sun exposure; in fact, BME accounts also intermediate exposures of the wind rose (i.e., North-West, North-East, South-West, South-East), while the proposed algorithm accounts for North, East, South and West only, thus causing a certain deviation from the real situation;

- A different length of the cooling season was considered, since Italian standards require a complex procedure to determine it and, in their first approach, authors convened not to deepen this aspect;

- Unconditioned thermal zones, such as the staircase zone, are not modeled in detail as in BME;

- Default constant values are assigned to frame factor (the ratio between the front surface of the window frame and the total front surface of the window), shading coefficient and time constant of the building; in this case, they were considered $0.23,1.00$ and $20 \mathrm{~h}$, respectively;

- Acceptable imprecision in net dimensions: $0.26 \%$ and $0.16 \%$ for net surface and volume, respectively.

In conclusion, the preliminary validation of the energy assessment methodology can be considered acceptable; nevertheless, the authors will investigate the possibility of further improving its quality, but only if an increase in the number of input data leads to a relevant refinement of the calculations.

\section{Conclusions}

In this study, a methodology for the development of a decision support tool is presented. In a quick, simple and effective way, the proposed DSS aims at identifying the best renovation scenario for an existing building, on the basis of a preliminary selection of the evaluation criteria (e.g., costs and duration of the intervention, disruption to the occupants, environmental sustainability, energy efficiency, thermal comfort, structural safety).

Although presenting limitations and simplifications, the proposed methodology focuses on setting up a quick and user-friendly DSS aimed at representing a reliable tool for the comparative assessment of structural, energetic and economic performance among different possible renovation scenarios, therefore taking into account the relative environmental sustainability, implementation time and cost, and disruption to the occupants. Furthermore, it should be noted that this tool aims also at a reduced expenditure of computational time and resources, since the application of a rigorous and precise procedure would instead be excessively burdensome. These considerations are particularly relevant, especially for those users who deal with the management of a large real estate. The reliability of the algorithms included in the DSS to evaluate the energy needs has been positively validated through energy simulations on a typical apartment building representative of a large part of the Italian residential stock built between during 1950-1990. More in detail, the deviation between the results of the proposed algorithms and those of the commercial software tool is below $4 \%$.

This research study is still ongoing and next steps will deal with the calibration of the methodology through its application to an appropriate number of buildings, the comparison of the results to the ones of other consolidated tools, and the possibility to apply artificial intelligence techniques and fuzzy logic approach to the DSS. The final outcomes might contribute to a larger implementation of combined renovation projects, with economic and social benefits due to the lower waste of money and time, the higher convenience to users, the better quality of life in terms of thermal comfort and seismic safety, as well as improving the psycho-physical well-being of the building occupants.

Author Contributions: Overall conceptualization, A.A., R.C. and G.M.; case study and simulations, A.A.; supervision of ICT issues, R.C. and E.M.; supervision of building construction and cost issues, G.M.; supervision of structural issues, E.M.M.; supervision of energy-efficiency issues, G.E.; writing-original draft, A.A.; writing-review and editing A.A., R.C., G.E., G.M. and E.M.M. All authors have read and agreed to the published version of the manuscript.

Funding: This research was partially funded by the University of Catania in the framework of the SIS-RENEW research project (Piano di incentivi per la Ricerca 2020-2022) and by ANCE Catania that financed a doctoral position for the development of the proposed application. 
Conflicts of Interest: The authors declare no conflict of interest. The funders had no role in the design of the study; in the collection, analyses, or interpretation of data; in the writing of the manuscript, or in the decision to publish the results.

\section{References}

1. E.B.S. Observatory. EU Building Stock Observatory. 25 November 2016. Available online: https://ec.europa. eu/energy/eu-buildings-factsheets_en (accessed on 10 July 2020).

2. Buildings Performance Institute Europe. State of the Building Stock Briefing; BPIE: Brussels, Belgium, 2017.

3. Economidou, M.; Laustsen, J.; Ruyssevelt, P.; Staniaszek, D. Europe's Buildings under the Microscope. A Country-By-Country Review of the Energy Performance of Buildings; BPIE: Brussels, Belgium, 2011.

4. La Greca, P.; Margani, G. Seismic and energy renovation method for sustainable cities. Sustainability 2018, 10, 254. [CrossRef]

5. Law Decree 63/2013. In Disposizioni Urgenti per il Recepimento della Direttiva 2010/31/UE del Parlamento Europeo e del Consiglio del 19 Maggio 2010, sulla Prestazione Energetica nell'Edilizia per la Definizione delle Procedure d'Infrazione Avviate dalla Commissione Europea, Nonche' Altre Disposizioni in Materia di Coesione Sociale; n.130 del 05/06/2013; Gazzetta Ufficiale della Repubblica Italiana: Roma, Italy, 2013. (In Italian)

6. Law 77/2020. In Conversione in Legge, con Modificazioni, del Decreto-Legge 19 Maggio 2020, n. 34, Recante Misure Urgenti in Materia di Salute, Sostegno al Lavoro e all'Economia, Nonche' di Politiche Sociali Connesse all'Emergenza Epidemiologica da COVID-19; n.180 del 18/07/2020; Gazzetta Ufficiale della Repubblica Italiana: Roma, Italy, 2020. (In Italian)

7. Law 145/2018. In Bilancio di Previsione dello Stato per l'Anno Finanziario 2019 e Bilancio Pluriennale per il Triennio 2019-2021 (Legge di Bilancio 2019); n.302 del 31/12/2018; Gazzetta Ufficiale della Repubblica Italiana: Roma, Italy, 2018. (In Italian)

8. Ministerial Decree n.58 of 28/02/2017 and Subsequent Amendments and Additions. Linee Guida per la Classificazione del Rischio Sismico delle Costruzioni nonché le Modalità per l'Attestazione, da parte di Professionisti Abilitati, dell'Efficacia degli Interventi Effettuati, e Disposizioni Attuative del Sismabonus. Ministero delle Infrastrutture e dei Trasporti. Available online: https://www.mit.gov.it/sites/default/files/media/normativa/2 017-03/Decreto\%20Ministeriale\%20numero\%2058\%20del\%2028-02-2017.pdf (accessed on 10 July 2020).

9. Barbagallo, F.; Hamashima, I.; Hu, H.; Kurata, M.; Nakashima, M. Base shear capping buildings with graphite-lubricated bases for collapse prevention in extreme earthquakes. Earthq. Eng. Struct. Dyn. 2016, 46, 1003-1021. [CrossRef]

10. Barbagallo, F.; Bosco, M.; Marino, E.M.; Rossi, P.P. Seismic retrofitting of braced frame buildings by RC rocking walls and viscous dampers. Earthq. Eng. Struct. Dyn. 2018, 47, 2682-2707. [CrossRef]

11. Della Corte, G.; D'Aniello, M.; Landolfo, R. Field Testing of All-Steel Buckling-Restrained Braces Applied to a Damaged Reinforced Concrete Building. J. Struct. Eng. 2015, 141, D4014004. [CrossRef]

12. Formisano, A.; Massimilla, A.; Di Lorenzo, G.; Landolfo, R. Seismic retrofit of gravity load designed RC buildings using external steel concentric bracing systems. Eng. Fail. Anal. 2020, 111, 104485. [CrossRef]

13. Pohoryles, D.; Maduta, C.; Bournas, D.A.; Kouris, L. Energy performance of existing residential buildings in Europe: A novel approach combining energy with seismic retrofitting. Energy Build. 2020, 223, 110024. [CrossRef]

14. Marini, A.; Passoni, C.; Belleri, A.; Feroldi, F.; Preti, M.; Metelli, G.; Riva, P.; Giuriani, E.; Plizzari, G. Combining seismic retrofit with energy refurbishment for the sustainable renovation of RC buildings: A proof of concept. Eur. J. Environ. Civ. Eng. 2017, 21, 1-21. [CrossRef]

15. Ferrante, A.; Mochi, G.; Predari, G.; Badini, L.; Fotopoulou, A.; Gulli, R.; Semprini, G. A European Project for Safer and Energy Efficient Buildings: Pro-GET-onE (Proactive Synergy of inteGrated Efficient Technologies on Buildings' Envelopes. Sustainability 2018, 10, 812. [CrossRef]

16. D'Urso, S.; Cicero, B. From the Efficiency of Nature to Parametric Design. A Holistic Approach for Sustainable Building Renovation in Seismic Regions. Sustainability 2019, 11, 1227. [CrossRef] 
17. Calvi, G.M.; Sousa, L.; Ruggeri, C. Energy Efficiency and Seismic Resilience: A Common Approach. In Multi-hazard Approaches to Civil Infrastructure Engineering; Springer Science and Business Media LLC: Berlin/Heidelberg, Germany, 2016; pp. 165-208.

18. Bournas, D. Innovative Materials for Seismic and Energy Retrofitting of the Existing EU Buildings, EUR 29184 EN.; Publications Office of the European Union: Luxembourg, 2018; ISBN 978-92-79-81995-7. JRC109907. [CrossRef]

19. Bournas, D. Concurrent seismic and energy retrotting of RC and masonry building envelopes using inorganic textile-based composites combined with insulation materials: A new concept. Compos. Part B Eng. 2018, 148, 166-179. [CrossRef]

20. Ferrante, A.; Mochi, G.; Predari, G.; Badini, L.; Fotopoulou, A.; Gulli, R.; Semprini, G. A European Project for Safer and Energy Efficient Buildings: Pro-GET-One (Proactive Synergy of inteGrated Efficient Technologies on Buildings' Envelopes. Sustainability 2019, 10, 812. [CrossRef]

21. Feroldi, F.; Marini, A.; Belleri, A.; Passoni, C.; Riva, P.; Preti, M.; Giuriani, E.; Plizzari, G. Sustainable seismic retrofit of modern RC buildings through an integrated structural, energetic and architectural approach adopting external engineered double skin façades. Progett. Sismica 2014, 5, 1-15.

22. Mazzolani, F.M.; Della Corte, G.; D'Aniello, M. Experimental analysis of steel dissipative bracing systems for seismic upgrading. J. Civ. Eng. Manag. 2009, 15, 7-19. [CrossRef]

23. Manfredi, V.; Masi, A. Seismic Strengthening and Energy Efficiency: Towards an Integrated Approach for the Rehabilitation of Existing RC Buildings. Buildings 2018, 8, 36. [CrossRef]

24. Artino, A.; Evola, G.; Margani, G.; Marino, E.M. Seismic and Energy Retrofit of Apartment Buildings through Autoclaved Aerated Concrete (AAC) Blocks Infill Walls. Sustainability 2019, 11, 3939. [CrossRef]

25. Margani, G.; Evola, G.; Tardo, C.; Marino, E.M. Energy, Seismic, and Architectural Renovation of RC Framed Buildings with Prefabricated Timber Panels. Sustainability 2020, 12, 4845. [CrossRef]

26. Kamari, A.; Jensen, S.; Christensen, M.L.; Petersen, S.; Kirkegaard, P.H. A hybrid Decision Support System for Generation of Holistic Renovation Scenarios-Cases of Energy Consumption, Investment Cost, and Thermal Indoor Comfort. Sustainability 2018, 10, 1255. [CrossRef]

27. Kamari, A.; Corrao, R.; Kirkegaard, P. Towards the development of a Decision Support System (DSS) for building renovation: Domain Mapping Matrix (DMM) for sustainability renovation criteria and renovation approaches. In Proceedings of the International Conference Catania, Seismic and Energy Renovation for Sustainable Cities, Catania, Italy, 1-3 February 2018.

28. Danilovic, M.; Browning, T.R. Managing complex product development projects with design structure matrices and domain mapping matrices. Int. J. Proj. Manag. 2007, 25, 300-314. [CrossRef]

29. Yang, J.; Ogunkah, I.C.B. A Multi-Criteria Decision Support System for the Selection of Low-Cost Green Building Materials and Components. J. Build. Constr. Plan. Res. 2013, 1, 89-130. [CrossRef]

30. Campos, A.R.; Neves-Silva, R. Decision support system for building renovation. In Proceedings of the 10th Portuguese Conference on Automatic Control, Funchal, Portugal, 16-18 July 2012.

31. Leone, M.; Zuccaro, G. Seismic and energy retrofitting of residential buildings: A simulation-based approach. J. Urban Plan. Landsc. Environ. Des. 2016, 1, 11-25.

32. CORDIS-EU Research Results. Modelling Crisis Management for Improved Action and Preparedness (CRISMA). Available online: https://cordis.europa.eu/project/id/284552. (accessed on 18 September 2020).

33. Ente Nazionale Italiano di Unificazione. Prestazioni energetiche degli edifici Parte 1: Determinazione del fabbisogno di energia termica dell'edificio per la climatizzazione estiva ed invernale. In UNI/TS 11300-1; UNI: Roma, Italy, 2014.

34. Ente Nazionale Italiano di Unificazione. Materiali da costruzione. Conduttività termica e permeabilità al vapore. In UNI 10351; UNI: Roma, Italy, 1994.

35. Ente Nazionale Italiano di Unificazione. Murature e solai. Valori della resistenza termica e metodo di calcolo. In UNI 10355; UNI: Roma, Italy, 1994.

36. Ente Nazionale Italiano di Unificazione. Prestazione termica di finestre, porte e chiusure oscuranti-Calcolo della trasmittanza termica. In UNI 10077; UNI: Roma, Italy, 2018. 
37. Inter-Ministerial Decree 26/06/2015. Applicazione delle Metodologie di Calcolo delle Prestazioni Energetiche e Definizione delle Prescrizioni e dei Requisiti Minimi degli Edifici. Ministero dello Sviluppo Economico. Available online: https://www.mise.gov.it/index.php/it/normativa/decreti-interministeriali/2032966-decreto-intermi nisteriale-26-giugno-2015-applicazione-delle-metodologie-di-calcolo-delle-prestazioni-energetiche-e-de finizione-delle-prescrizioni-e-dei-requisiti-minimi-degli-edifici (accessed on 21 July 2020).

38. Smith, S. ASP.NET. Overview of ASP.NET Core MVC. Available online: https://docs.microsoft.com/it-it/asp net/core/mvc/overview?view=aspnetcore-3.1. (accessed on 21 September 2020).

39. Università degli Studi di Bologna. RE.SIS.TO Resistenza Sismica Totale. RE.SIS.TO Project. Available online: https://www.resistoproject.com/ (accessed on 21 July 2020).

40. Chinni, C.; Mazzotti, C.; Savoia, M.; Perri, G. RE.SIS.TO.: Una metodologia speditiva per la valutazione di vulnerabilità sismica di edifici in muratura e calcestruzzo armato. In Proceedings of the XV Convegno ANIDIS-L'Ingegneria Sismica in Padova, Padova, Italia, 30 June-4 July 2013.

41. Dolce, M.; Masi, A.; Moroni, C.; Liberatore, D.; Laterza, M.; Ponzo, F.; Cacosso, A.; D’Alessandro, G.; Faggella, M.; Gigliotti, R.; et al. Valutazione della vulnerabilità sismica di edifici scolastici della Provincia di Potenza. In Proceedings of the XI Congresso Nazionale "L'ingegneria Sismica in Italia", Genova, Italy, 25-29 January 2004.

42. GNDT. Gruppo Nazionale per la Difesa dai Terremoti. Available online: https:/emidius.mi.ingv.it/GNDT/. (accessed on 21 July 2020).

43. Ferreira, T.M.; Rodrigues, H.; Vicente, R. Seismic Vulnerability Assessment of Existing Reinforced Concrete Buildings in Urban Centers. Sustainability 2020, 12, 1996. [CrossRef]

44. Ministero delle Infrastrutture e dei Trasporti. Aggiornamento delle Norme Tecniche per le Costruzioni-NTC2018; Gazzetta Ufficiale della Repubblica Italiana: Roma, Italy, 2018. Available online: https://www.gazzettaufficia le.it/eli/gu/2018/02/20/42/so/8/sg/pdf (accessed on 23 September 2020).

45. Ministry of Economic Development. Inter-Ministerial Decree 26 June 2015; Adeguamento Linee Guida Nazionali per la Certificazione Energetica Degli Edifici. Allegato 1; Gazzetta Ufficiale della Repubblica Italiana: Roma, Italy, 2015. Available online: https://www.mise.gov.it/index.php/it/normativa/decreti-interministeriali/2032968-d ecreto-interministeriale-26-giugno-2015-adeguamento-linee-guida-nazionali-per-la-certificazione-energ etica-degli-edifici (accessed on 23 September 2020).

46. ITC-CNR and ENEA. DOCET. Available online: http://www.docet.itc.cnr.it/ (accessed on 23 September 2020).

47. Ente Nazionale Italiano di Unificazione. Prestazioni Energetiche Degli Edifici Parte 2: Determinazione del Fabbisogno di Energia Primaria e Dei Rendimenti per la Climatizzazione Invernale, per la Produzione di Acqua Calda Sanitaria, per la Ventilazione. In UNI/TS 11300; UNI: Roma, Italy, 2019.

48. Ente Nazionale Italiano di Unificazione. Riscaldamento e raffrescamento degli edifici-Dati climatici. In UNI 10349; UNI: Roma, Italy, 2016.

49. Baldoni, E.; Coderoni, S.; D’Orazio, M.; Di Giuseppe, E.; Esposti, R. The role of economic and policy variables in energy-efficient retrofitting assessment. A stochastic Life Cycle Costing methodology. Energy Policy 2019, 129, 1207-1219. [CrossRef]

50. Guardigli, L.; Bragadin, M.A.; Ferrante, A.; Gulli, R. Life cycle analysis and planning in the renovation process of public housing. Technol. Eng. Mater. Archit. 2019, 5, 106-119.

51. Ascione, F.; Cheche, N.; De Masi, R.F.; Minichiello, F.; Vanoli, G.P. Design the refurbishment of historic buildings with the cost-optimal methodology: The case study of a XV century Italian building. Energy Build. 2015, 99, 162-176. [CrossRef]

52. Cirami, S.; Evola, G.; Gagliano, A.; Margani, G. Energy Renovation Strategies for Historical Buildings: Cost-Optimal Analisys for a Case Study in Catania (Sicily). In Proceedings of the Historical Buildings Retrofitin the Mediterranean Area, Matera, Italy, 12-13 May 2017.

53. Directive E.U. European Parliament, Directive (EU) 2018/844 of the European Parliament and of the Council of 30 May 2018 Amending Directive 2010/31/EU on the Energy Performance of Buildings and Directive 2012/27/EU on Energy Efficiency (Text with EEA relevance). Official Journal of the European Union. 2018. Available online: https:/eur-lex.europa.eu/eli/dir/2018/844/oj (accessed on 12 October 2020).

54. Ente Nazionale Italiano di Unificazione. Prestazione Energetica degli Edifici-Sistemi di Riscaldamento e Sistemi di Raffrescamento Idronici negli Edifice-Parte 1: Procedura di Valutazione Economica per i Sistemi Energetici negli Edifici, Modulo M1-14. In UNI EN 15459-1; UNI: Roma, Italy, 2018. 
55. Ministero delle Infrastrutture e dei Trasporti. Circolare 7/2019 del C.S.LL.PP. Istruzioni per l'Applicazione dell'Aggiornamento delle Norme Tecniche per le Costruzioni; Gazzetta Ufficiale della Repubblica Italiana: Roma, Italy, 2019. Available online: https://www.gazzettaufficiale.it/eli/id/2019/02/11/19A00855/sg (accessed on 12 October 2020).

56. Jansen, B.W.; Van Stijn, A.; Gruis, V.; Van Bortel, G. A circular economy life cycle costing model (CE-LCC) for building components. Resour. Conserv. Recycl. 2020, 161, 104857. [CrossRef]

57. Proitaca SRL. Protocollo ITACA (Istituto per l'Innovazione e Trasparenza degli Appalti e la Compatibilità Ambientale). Available online: https://www.proitaca.org/ (accessed on 24 September 2020).

Publisher's Note: MDPI stays neutral with regard to jurisdictional claims in published maps and institutional affiliations.

(C) 2020 by the authors. Licensee MDPI, Basel, Switzerland. This article is an open access article distributed under the terms and conditions of the Creative Commons Attribution (CC BY) license (http://creativecommons.org/licenses/by/4.0/). 